\title{
Stylistic Study of Adjectives in How to Get Filthy Rich in Rising Asia
}

\author{
Rabia Faiz ${ }^{1}$, Musarrat Azher ${ }^{1}$, Ijaz Asghar ${ }^{1} \&$ Iqra Jabeen $^{1}$ \\ ${ }^{1}$ Department of English, University of Sargodha, Sargodha, Pakistan \\ Correspondence: Musarrat Azher, Department of English, University of Sargodha, Pakistan. E-mail: \\ musrratazher@gmail.com
}

Received: January 26, 2018 Accepted: February 13, 2018 Online Published: February 24, 2018

doi:10.5539/ijel.v8n3p328 URL: http://doi.org/10.5539/ijel.v8n3p328

\begin{abstract}
The present research explores the choice of adjectives as a lexical category in Mohsin Hamid's novel, How to Get Filthy Rich in Rising Asia by using Leech and Short model (1981). An empirical enquiry is carried out to trace the author's choice of adjectives and their intended functions by subjecting How to Get Filthy Rich in Rising Asia to stylistic analysis and linguistic scrutiny. The various functions of adjectives are interpreted after the text is subjected to close reading for their contextual occurrence where they are carefully engraved by the author. The resultant functions throw ample light on the life, culture, economic scenario and love and gender relations construed in the text through adjectives. The present paper, however, is limited only to the interpretation of the adjective categories based on the model suggested by Leech \& Short (1981). This study is, therefore, instrumental in initiating a voyage to interpret literary language via linguistic tools and evidences contributing amply to the field of stylistics as well as literary criticism.
\end{abstract}

Keywords: stylistic analysis, lexical choices, adjectives

\section{Introduction}

There is a scarcity of research on literature by Pakistani writers and, although, Pakistan is one of the major countries providing raw material for historical and colonial research, it has been kept out of detailed positioning in the critique of post-Partition literature in theory and in specific research arenas, especially history and feminism. Conclusively, there is a need by researchers from Asian context to redefine the presentation of Asia in the works of leading Asian authors in English for a better understanding and thought presentation of Asian world.

Hanif Kureishi, Adam Zameenzad, Bapsi Sidhwa and Nadeem Aslam are a few more prolific artists who have not merely contributed to the fountain of literature but they have also won pride for Pakistan in the form of many major prizes in literature. These writers have diverted themselves from the traditional issues of nationalistic and socialist concern but, within their very nature, they contain many political, communal as well as commercial questions of the present day interest.

\subsection{Mohsin Hamid and How to Get Filthy Rich in Rising Asia}

Mohsin Hamid is one of the highly acclaimed Pakistani authors in English. Mohsin Hamid's talent in fiction writing has raised the status of Pakistani writings in English and has received much appreciation in the international media. His major works, Moth Smoke, The Reluctant Fundamentalist, How to Get Filthy Rich in Rising Asia and Exit West have been great reading sensations because of the unique treatment of theme, subject matter and innovation of style and expression. How to Get Filthy Rich in Rising Asia is a fantastic study or an exploration through the life of a self made protagonist from an impoverished beginning to an ordinary death in some city in rising Asia. The novel under study is an imitation of a Self-help book having twelve steps, in the form of twelve chapters, containing "useful" (p. 3) insights into becoming rich and upgrading economic status in the rising world of the East. Set in a fictional city of Asia, centered around a fictional protagonist "you" from his infancy to death in 70s, Hamid's work is emphatic in vividly presenting the personal tale of loss in the pursuit of economic fortification which is the lot of many ambitious persona in Asia in the contemporary age.

The present paper tries to unfold the use of adjectives in the above stated novel in order to see the peculiarity of style of Mohsin Hamid through his lexical choices in the text. Leech and Short model is instrumental because it gives an impressive frame of analysis for the beginners interested in the study of style in fiction. The adjectives 
are discussed on the basis of the attributes they represent in the text, their gradability and non gradablility and their predicative and attributive position in the text.

The research is significant as it lays ample emphasis along with evidence on how specific theme and function is related with the particular choice of language used by a writer. The researcher has employed linguistic devices to support the philosophical as well as literary interpretations and meanings that emerge from these choices. It can lead to a number of research prospects for the future researchers who want to study different aspects of Mohsin Hamid's novels through literary or linguistic analysis.

\subsection{Purpose of the Study}

The purpose of undertaking this research has been to explore the relationship between lexical choices and their function through a stylistic analysis of How to Get Filthy Rich in Rising Asia by Mohsin Hamid at the level of adjectives. The outcome of research throws light on the usefulness of these choices in relaying meaning in the text and how stylistic evidences perform the function of elaboration of meanings in a text.

\subsection{Significance of the Study}

The study of lexical choices using Leech and Short model is unique in the sense that it tries to bridge up the literary and linguistic investigation via stylistic analysis. Evidently, lexical choices have played an important role in helping Mohsin Hamid to pinpoint various cultural, social and commercial aspects of his native country or an unnamed country with unnamed characters and places but vividly revealing Asia in general at every page of his novel, How to Get Filthy Rich in Rising Asia. It can be instrumental in unearthing broad stylistic patterns to reach towards intuitive generalizations about literary texts. These exciting and innovative advances in the field of stylistics will not only be an aid to critics and researchers but also add to the scholarship on highly celebrated author of our times, Mohsin Hamid. Moreover, the present research will also be an asset to the significance of Pakistani literature in English in the field of research.

\subsection{Population and Sample of Study}

The novel How to get Filthy Rich in Rising Asia by Mohsin Hamid published in the year 2013 has been selected and collected as a sample for the Stylistic analysis with a focus on the lexical choices of adjectives and their specific function in the text.

\subsection{Delimitations of the Study}

The study is limited in the following ways:

- Due to limitation of time and resources, the present research is limited to the stylistic analysis of only one novel by Mohsin Hamid, that is, How to Get Filthy Rich in Rising Asia.

- Only one item (adjectives) from the lexical domain is selected to study the style of Hamid in How to Get Filthy Rich in Rising Asia and to observe the significance of adjectives in relaying meaning in the text.

\subsection{Research Questions}

The present paper strives to answer the following questions:

- What kinds of adjectives are used in How to Get Filthy Rich in Rising Asia?

- What is the utility of the various kinds of adjectives used in the text?

- Whether the use of adjectives shows any peculiarity of Hamid's style as a novelist or not?

\section{Critical Review of Literature}

Stylistics in the twenty-first century is a living area of research which is taught and researched in university departments of language, literature and linguistics. Stylistics enjoys high academic profile that is reflected in the number of its dedicated book-length publications, research journals, international conferences and symposia, and scholarly associations. Modern stylistics is positively progressing that can be observed in an increase of sub-disciplines where stylistic methods are supplemented by theories of discourse, culture and society (Simpson, 2004).

The concept of style is as old as the foundation of literary thought in Europe. Due to its connection with rhetoric, the ancient tone of style is basically prescriptive (Hough, 1969). In 1960s, descriptive linguists used the term "style" to point towards general situational varieties where it was treated as an attribute of language (Biber \& Conrad, 2009). Leech (2007) unfolds the controversial position of style jolting between form and manner. For Hough (1969), style is an "aspect of meaning" and a matter of choice. It follows that the choice of subject matter 
is not stylistic in nature whereas the choice of verbal means, that is, the use of varied lexical or syntactic resources employed to express that very subject matter, definitely is stylistic one.

When different styles are linguistically studied, we are in the domain of Stylistics (Chapman, 1973). For Simpson (2004), Stylistics is a method of textual interpretation in which the language is focused. Style has several dimensions and a Linguist seeks for the justification of a particular style or a specific expression (Leech \& Short, 2007). Shaikh (2011) highlights Stylistics as a road connecting Linguistics to Discourse studies dealing with mind and communication. Leech (1985) is of the view that stylistics serves as the area where linguistics and critical exegesis overlap. Hence, Literary Stylistics is a podium where linguistic and literary interpretations may simultaneously be generated out of a text.

Style is alexical and grammatical feature in a text that escorts the analyst to the meaning of the text. The choice of certain lexical items and their repetition using specific syntactic structures and employing various literary devices are the interest areas of stylistic analyst to probe into the relation between author's choice of language and its function. Leech (2008) describes the concept of foregrounding in a literary text. The normal patterns of language provide background for the deployment of certain deviations from the norm. Literary Stylistics is the study of a literary text with the aim of decoding structural features by identifying linguistic patterns and their functions in the text (Starke, 2010).

Two methods of Stylistics are in vogue from research perspective. One of them is the traditional method and the other is the Corpus Stylistics analysis. The traditional method analyses the text at four levels: lexical, graphological, syntactic and semantic level (Li, 2009). Corpus Stylistics is advancement in the study of style using computer aided methodology in the analysis of text via language collected and incorporated in corpora (Wyne, 2005).

Corpus linguistics has opened up a new research arena for the empirical and quantitative analysis of the literary text. Over the past several decades, numerous stylistics studies of literary language using computational techniques of words analysis have emerged. These researches have come to be associated with corpus linguistics, carried out under the head of Corpus stylistics (Biber, 2011).

Many Stylistic researchers have brought forward valuable studies in this field to analyze word classes that help to generate the relation between choice and function. The present study also aims to carry forward this tradition in the Asian context to reach Stylistic interpretation generated through certain lexical items. Adjectives are the focal lexical items to gauge what function they relay in the text under evaluation. In order to perform a linguistic or stylistic analysis, a checklist of linguistic and stylistic categories is devised by Leech \& Short (1981). The list includes four categories, namely, Lexical (general, nouns, adjectives, verbs and adverbs), Grammatical (sentence types, sentence complexity, clause types, clause structure, noun phrases, verb phrases, other phrase types, word classes and general), Figures of speech and Context and cohesion (Leech \& Short, 1981).

Lexical feature is concerned with the choice of specific lexical items and their distribution and relation among themselves, and the way they generate meaning in the text. To examine a text in terms of its lexicon can unleash sources of cohesion that might not otherwise be noticed and their study can lead to the discovery of recurrent themes and images in a text under analysis (Traugott \& Pratt, 1980).

In traditional terms, adjective modifies the meaning of the noun. It describes a person, place, quantity or a value. Adjective has two main characteristics, semantic and syntactic. On the semantic level, it may characterize properties, while on syntactic plane; it may function as a modifier. Quirk, Greenbaum, Leech, \& Svartvik (1985) give a detailed account of adjectives. Quirk (1985) explains the syntactic function of adjectives by pointing towards three positions of adjectives in a sentence, which are, predicative, attributive and post positive. The analysis of adjectives can be founded on the basis of morphological, syntactic and semantic functions (Biber, Johnson, Leech, Conrad, \& Finegan, 1999).

Many researchers have focussed on the study of adjectives in English fiction and non-fiction. Kaunisto (2007) studies the lexical competition through the use of corpora providing the diachronic examination of word formation in the study of English adjectives that end in -ic and -ical. Payne, Huddleston, \& Pullum (2010) have worked on the issue of complementarily of adverb and adjective in English which according to them does not apply as a rule in English language. A Corpus based study of adjectives in Pakistani fiction has been carried out by Mehmood \& Nawaz (2014) where the researchers have focused on the use of adjectives and the impact created by their use in the fictional world of Bapsi Sidwah.

Hamid's third novel, the focus of the present research, How to Get Filthy Rich in Rising Asia, was released in March 2013 by Riverhead Books. His innovative tradition is continued in case of How to Get Filthy Rich in 
Rising Asia in which the conventions of both genre and form have been blended to achieve a particular function in text. Initially the novel seems filled with a clumsy narrative technique but it actually allows the author to zoom in and out of his character's life as if he uses a telephoto lens to do that (Kakutani, 2013). Khan (2013) models his research on the major works of four Pakistani authors, that are, Mohsin Hamid's The Reluctant Fundamentalist (2007) and How to Get Filthy Rich in Rising Asia (2013), Kamila Shamsie's Burnt Shadows (2008), Nadeem Aslam's The Wasted Vigil (2008) and Daniyal Mueenuddin's In Other Rooms, Other Wonders (2009).This study undertakes the input of contemporary Anglophone Pakistani writers in providing alternative account on the issue of Pakistani identity and selfhood, transforming and revitalising the naturalized image of the country to the international reading circle and this reimagining of Pakistan functions within the framework of transnationalism in order to look forward to a political state of togetherness despite differences. A research on Hamid's narrative technique in How to Get Filthy Rich in Rising Asia is carried on by Chao (2014) who states the function of using second person narration and taking the self help form not as a medium of parody but as a means of satire to reach the ultimate shattering of ambitions and dreams of becoming rich in an Asian context while following the steps created in the wake of American dream.

Taking stock of the literature in this section, the present paper looks forward to present methodology and findings with the help of stylistic analysis of Hamid's novel where the lexical choices of adjectives and the function that such choices owe are the basic interest of the research at hand. In this way the present study amply adds to the research on Hamid's fiction and it fills the gap in the study of this novel that was previously restricted to the implementation of critical theory on this text.

\subsection{Theoretical Framework}

The present paper analyzes the novel How to get Filthy Rich in Rising Asia via stylistic analysis upon a certain word class i.e. Adjectives. The study attempts to gain further insights into the text with the help of these linguistic features. The research details the insight through the discussion incurred in result of the data. The process of the research has been planned and executed utilizing qualitative design of research. The stylistic analysis in the study of lexical choices supports the research questions at hand which have been designed with a focus on the empirical, exploratory and descriptive tendency of this research. For the qualitative methodology, close reading of Hamid's novel has been used followed by identification of adjectives, developing their categories, labeling of the categories leading to their interpretation with reference to their function.

In order to analyse the adjectives, the Leech \& Short (1981) model has been used at the very basic level which is quite instrumental in helping any researcher aiming to approach a work of literature with the linguistic or stylistic tools of analysis. According to the categories of analysis presented by Leech and Short (1981), the present research is based on the Lexical Category of Adjectives which is elaborated by Leech and Short (1981) in the following manner:

"A: Lexical categories

3. ADJECTIVES. Are the adjectives frequent? To what kinds of attributes do adjectives refer? physical? psychological? visual? auditory? color? referential? emotive? Evaluative?etc. Are adjectives restrictive or non-restrictive? Gradable or non-gradable? Attributive or predicative?" (p. 76).

The adjectives in the novel under study have been categorized on the basis of following features extracted from Leech \& Short (1981):

Adjectives referring to physical, psychological, visual, auditory, color and emotive attributes

Gradable and non-gradable adjectives

Attributive and predicative adjectives

The detailed files consisting of the relevant textual instances have been made for the study of each category of adjectives. Within the qualitative arena, data has been manually collected and marked by the researcher. The selected raw data has been categorized and sub categorized and separate tables for each kind of adjective under study and adjective clusters according to function have been made. After sorting out adjectives according to kind and function, data has been analysed to give conclusion about the style of Mohsin Hamid as anovelist.

A great care has been taken to ensure the validity and reliability of data organization and analysis. Following are some of the measures taken in this context:

Two research assistants were trained who also worked with me to sort out the adjectives into the categories that have been mentioned above. The findings on these research assistants were compared and reconciled with my 
own in order to remove any subjectivity and to make the process of tabulation error free in the maximum possible manner.

\section{Data Analysis and Discussion}

Mohsin Hamid's novel, How to Get Filthy Rich in Rising Asia, written in the form of a self help book, demonstrates a number of features of Asian society through the use of adjectives which enables the readers to gauge the reality embedded in the text of the novel.

All the adjectives in the novel have been organized in the form of a table. A comprehensive view of the use of adjectives on the basis of the categories defined by Leech \& Short (1981) is presented in the following discussion. These adjectives have been divided on the basis of the attributes they discern, gradability and their attributive or predicative position in a sentence.

\subsection{Hamid's Adjectives Referring to Specific Attributes}

In order to enable the reader to comprehend and imagine the fictional world created by an author through the specific choices of lexical items, adjectives function as key ingredients that are embedded in the structure of any text for creating a vivid and elaborate vision. This idea is fairly relevant with reference to How to Get Filthy Rich in Rising Asia in which a close examination of the text reveals that a special aroma has been added in this work by Hamid with the special stroke of adjectives in a variety of forms referring to specific attributes. The presentation of physical, psychological, visual, auditory, color and emotive attributes via adjectives has been a source of creating vigour in the novel. The characters in the novel are described by adjectives denoting their physical and emotive attributes. The use of color, visual and auditory adjectives also supplements the physical and emotive attributes in order to establish a very vivid picture of the characters, both major as well as the minor.

\subsection{Adjectives and Physical Attributes}

The following table highlights some of the adjectives referring to the physical attributes of various characters; five of them have been used as a model of analysis.

Table 1. Adjectives and physical attributes

\begin{tabular}{lll}
\hline Sr. No. & Character & Adjectives \\
\hline 1. & Protagonist & Strong, young, adorable, sturdy, bald, mutating, flimsier, bony, thin, weak \\
2. & Mother & Physical vitality, solid ample thighs, powerful tongue, muscular twitches \\
3. & Pretty Girl & Pretty, beautiful, tall, lean, darker, persistent twinge, diminished form, zestful, aged \\
4. & Brother-in-law of Protagonist & Plump, squat, pale, masculinized, sensuous mouth, verbal tics \\
5. & Security Guard & Sharp, unsmiling eyes, barrel stomach, four silver teeth \\
\hline
\end{tabular}

The findings from the novel support the fact that Hamid creates a visual image of his characters by giving their physical traits via adjectives that for a clear picture of characters in the context of the plot. We can also say that Hamid is able to present a life-long picture of his characters by showing positive as well as negative qualities that can be described through physical attribution. If the protagonist is strong, young and adorable during his youth, he is also presented in his old age as mutating, flimsier and thin.

In the same way, the female leading character is called with the attributive adjective 'pretty' every time she appears till the last page of the novel. But the narrator of this self-help book shows life history of this zestful female character by use of a trajectory of adjectives starting from pretty, beautiful and tall towards lean, diminished and aged.

The mother of the protagonist also passes from strength to physical failing owing to cancer. She had solid ample thighs but her disease reduced them to muscular twitches and then the powerful tongue turns into calm and quiet of death overtaking her senses for good.

The same is the case with the characters of the brother-in-law of the protagonist and the security guard. These adjective choices are evidences to show how adjectives presenting physical attributes describe the characters according to their age and circumstances. Thus they are helpful in the analysis of characterization by an author.

\subsection{Adjectives and Emotive Attributes}

It is evident from the study of a novel with respect to adjectives that their specific choices invoke emotional responses. Presenting the emotive attributes of characters and events with the help of adjectives create an emotional effect according to the context in which they are used. Hamid's choice of emotive words or group of 
words is never choppy or rough, but it is based on serious brooding over the situation that he creates and the suitable lexical items jump in to fit themselves into that situation. The novel under study contains emotive attributes presented through adjectives that are distributed equally in the whole fabric of the novel. Furthermore, these adjectives are not merely titled to one or two emotions but permeate to the invocation of all major emotions from love to bitterness, from joy to pain, from beauty to ugliness and from strength to weakness. Just like representation of physical attributes, the emotive language is also distributed amongst all the significant characters in the novel.

Table 2. Adjectives and emotive attributes

\begin{tabular}{|c|c|c|}
\hline $\begin{array}{l}\text { Sr. } \\
\text { No. }\end{array}$ & Evidences from Text & $\begin{array}{l}\text { Page } \\
\text { No. }\end{array}$ \\
\hline 1. & "You are instructed by a "single hollow-cheeked, betel-nut-spitting, possibly tubercular" teacher." & 21 \\
\hline 2. & $\begin{array}{l}\text { "One winter evening, when it is already dark, and the two of you approach each other in the unlit alley that cuts } \\
\text { through the factories, she speaks to you." }\end{array}$ & 42 \\
\hline 3. & $\begin{array}{l}\text { "She is thus doubly disarmed, of her physical vitality and of her powerful tongue, and when not exhausted she is } \\
\text { baffled, and at times angry." }\end{array}$ & 67 \\
\hline 4. & $\begin{array}{l}\text { "You are excited and nervous, but pleased by your appearance when you glimpse yourself in the mirror of } \\
\text { motorcycle, thinking your garb connotes wealth and class." }\end{array}$ & 83 \\
\hline 5. & $\begin{array}{l}\text { "His faith is strong and idiosyncratic, manifesting itself in prayer, visits to shrines, religious music, and sacred } \\
\text { verses written on paper and worn as amulets." }\end{array}$ & 93 \\
\hline 6. & $\begin{array}{l}\text { "Your conveyance is a micro pickup truck older than you are, the side panels of its rear bed holed through in } \\
\text { intricate, rusted filigree, but its noisy two-stroke engine rebuilt and reliable." }\end{array}$ & 102 \\
\hline 7. & $\begin{array}{l}\text { "She is aware that her future is shaky, that she could well end up impoverished, aged, and solitary, an elderly lady in } \\
\text { a single room, ..." }\end{array}$ & 111 \\
\hline 8. & $\begin{array}{l}\text { "You left your wife behind in the city, a decision experienced by her as hurtful, despite your claim that the journey } \\
\text { would be too arduous because of the floods." }\end{array}$ & 132 \\
\hline 9. & $\begin{array}{l}\text { "Perhaps no one does this with more single-minded dedication or curatorial ferocity than those at the apex of } \\
\text { organizations entrusted with national security." }\end{array}$ & 160 \\
\hline 10. & $\begin{array}{l}\text { "Frequently you have the impression of gazing with the pretty girl, as if from the lip of a cliff, off into a valley where } \\
\text { night is falling, a stark and } d r y \text { and contaminated valley, where perhaps all sorts of bony, mutating creatures abide, } \\
\text { many carnivorous, and ..., you know that carnivores feed especially on the old and the sick and the frail..." }\end{array}$ & 223 \\
\hline
\end{tabular}

Mohsin Hamid's use of emotive language is very exclusive and vital. Its function is to evoke emotions and responses from the readers and the adjectives used for incurring such emotions may or may not be abstract in nature. As the above table shows, in instance one, the author describes the physical traits of a teacher but the description brings upon the reader the responses of dislike and discomfort as the image presented breaks the very notion of esteem bracketed together with teachers culturally and traditionally in Asia.

Another aspect of his style of using adjectives is to create a graphical picture of a scenario which generates an automatic emotional response. The use of such lexical items as "winter, dark and unlit" in the second example in the table denotes a usual winter night but connotes sensual emotions arousing in that very context. In the similar fashion, in the example 8 given above, the "arduous" journey because of flood not simply creates a visual environment but also gives undertone of a wretched relation between the protagonist and his wife because of the memory of pretty girl always hovering over him.

At certain places in the text, Hamid uses opposites to achieve a balanced emotional response and, also, to add a tinge of complexity to the lives of his characters. In the third example, contrasting adjectives powerful and baffled, and in the fourth example, excited and pleased show that the specific choices of contrasting adjectives at the same situation and for the same character perform the same function of balance and complexity. Abstract ideas of faith, apprehension for the future, patriotism and death have been very well presented through the use of adjectives as cited in the examples 5,7,9 and 10 respectively.

These evidences show that the emorive use of adjectives correlates with abstract ideas in order to interpret text on the emotional scale as well.

\subsection{Adjectives and Vocal, Auditory and Color Attributes}

If compared with the physical, visual and emotive attributes, Hamid's use of vocal, auditory and color attributes seems scarce. Nevertheless, the importance of the latter cannot be denied as them being less frequent. They also perform specific functions to show that their choice is deliberate and purposive. These adjectives seem to catch 
the verbal and auditory channel in order to develop a contact among the characters and that of the readers beyond the level of written text and to enable the reader to enter into the world of characters created by the author in a vivid manner. After observing the vocal-auditory attributes presented via adjectives, the following discussion can be made based on the evidences in Table 3 .

Table 3. Vocal-auditory attributes

\begin{tabular}{lll}
\hline Sr. No & Adjectives & Attributes/Objects \\
\hline 1. & Traumatized & Respiration \\
2. & Hydraulic & Suction \\
3. & Muffled & Screams \\
4. & Distracted & Chant \\
5. & Foolhardy & Voice \\
6. & Hushed & Silence \\
7. & Powerful & Voice \\
8. & Steady & Voice \\
9. & Languid & Voice \\
10. & Hard & Talk \\
\hline
\end{tabular}

Here, the choice of adjectives to present vocal-auditory attributes shows a specific pattern. Almost all these adjectives connote strength and weakness of characters. When the voice is powerful and hard, the character is dominating in a situation but when a character's voice is languid, muffled and distracted, it shows weakness and lack of power. Thus it may be established with the evidences that power relations are also embedded in the adjective clusters of the text.

The following table shows the choice of color adjectives used in the text for specific meaning and comprehension.

Table 4. Adjectives and colour attributes

\begin{tabular}{lll}
\hline Sr. No & Adjectives & Attributes/Objects \\
\hline 1. & Yellow & Eyes \\
2. & White & Breaching \\
3. & Red & Meat \\
4. & Gray & Hair \\
5. & White-tufted & Ear Hair \\
6. & Black & Trousers \\
7. & Gold tinted & Windows \\
8. & Reflective & Flesh \\
9. & Brown & Swimsuit \\
10. & White & Teeth \\
\hline
\end{tabular}

It may be concluded from the random analysis of the use of adjectives to present the color attributes that most of these adjectives are chosen to present the physical features and attire of characters. The author takes the central position of an observer in this case and actually records the vivid images in his book and a description such as this gives a complete version of the characters as if they breathe in from of us. Since the characters appear from their youth to age, the colour images portray them in such a way that the growth of characters is well recognized with the assistance of adjectives.

\subsection{Gradable and Non-Gradable Adjectives}

Apart from the basic attributes expressed through adjectives, the nature and uqiueness of gradable and non-gradable adjectives is also a significant part of the present research findings. Use of grading adverbs and modifiers represent gradability of adjectives (Bolinger, 1967). There is a special link among gradability, truth condition and semantic function in a discourse. Though Baker (2003) finds nothing special about adjectives, they do hold an important position in the world of fiction for most of the Pakistani authors in English.

As far as How to Get Filthy Rich in Rising Asia is concerned, gradable and non-gradable adjectives form a pattern but we can deduce after careful scrutiny that his choice of gradable and non-gradable adjectives has hardly an peculiarity of style. The pattern that emerges shows that he uses grading adverbs with base forms of 
adjectives rather than using the comparative or the superlative. Some examples include: very strong, extremely high, absolutely clear, relatively good, very good and very small. It can further be deduced from such evidences that the author's choice of gradable adjectives is determind again by the purposive function of presenting everything in the novel as real as it could be without a sense of exaggeration that is reflected with the use of the superlative degree. Moreover, the grading adverbs function to emphasize rather than interfre with the degree of that particular characteristic expressed through adjectives.

Using the base form of adjectives also offers them a little flexibility. Same can be said of non-grading adjectives with which adverbs are prefixed for the sake of enhancing their impact without giving any impression of exaggeration.

\subsection{Choice and Function of Attributive and Predicative Adjectives}

In a certain stretch of language, adjectives may be sorted out on the basis of their attributive or predicative position. The adjectives in this novel have been classified into their attributive and predicative positions and the discussion is based on their function at different levels. Attributive adjectives emphasize action by being a permanent part of the subject whereas predicative adjectives qualify the noun or the subject. Concomitantly, these placements result in specific functions of these adjectives. Following conclusions may be drawn on the basis of observations in this regard:

Hamid's attributive adjectives are most of the times descriptive in nature. Choice of descriptive adjectives means that the author has stapled communicative function with such adjectives. They are the agents to convey the perception of the author to the readers as well as to create the reader's own perception about the context in which they are placed by the narrator. Table 5 shows some adjectives randomly selected that are used in the attributive position.

Table 5. Attributive adjectives

\begin{tabular}{lll}
\hline Sr. No. & Adjectives & Nouns/Attribute \\
\hline 1. & Poor & Man \\
2. & Filthy & Rich \\
3. & Rising & Asia \\
4. & Reassuring & Existence \\
5. & Unrecognizable & World \\
6. & New & Reality \\
7. & Romantic & Love \\
8. & Inevitable & Exit \\
9. & False & Hope \\
10. & Archetypal & Woman \\
\hline
\end{tabular}

Moreover, the use of attributive adjectives in How to Get Filthy Rich in Rising Asia also connotes for the state of permanence and persuasion. Physical world and social infrastructure have been described via attributive adjectives and their function is to show that still rising Asia is not able to grapple with those permanent entanglements which makes it difficult for the individuals to become victoriously rich in Rising Asia and thus, most of them adopt a filthy path of getting rich in rising Asia.

Where attributive adjectives convey permanence and persuasion, predicative adjectives in this novel connote to personal qualities, mood and behaviour of characters. Here again, the permanent state of a character is attributively presented and the changing or temporary state of emotions, feelings or being is conveyed through predicative position of adjectives. Table 6 contains some illustrations in this regard. 
Table 6. Predicative adjectives

\begin{tabular}{lll}
\hline Sr. No. & Adjectives & Subject \\
\hline 1. & Domineering and lazy & They \\
2. & Yellow & Eyes due to disease \\
3. & Warm & Evening \\
4. & Lucky & Day \\
5. & Soft & Tone of teacher \\
6. & Angry & Protagonist \\
7. & Hoarse & Voice \\
8. & Focussed & Gaze \\
9. & Formal and efficient & Wife of protagonist \\
10. & Solitary & Responsibility \\
\hline
\end{tabular}

All the above stated adjectives are used in predicative position and refer to temporary state of health, feeling, emotion and correspondence of different characters.

Generally speaking, English adjectives follow an explicit order: determiners/ articles, quantity, observation/opinion, size and shape, age, color, origin, material and qualifier. From the observation, it can be deduced that the adjectives stating origin are scarcely used in this novel because the focus is wholly concentrated on Asia and no comparison is made with characters, material things and situations outside this context, hence, less adjectives attributing origin can be seen. The adjective order is also not followed in any hard and fast manner but the choice of order is dependent on their appropriate use at specific position in sentences. Following are some of the ways adjectives are used in the novel:

"Old rusting and subscale textile plant (p. 7)."

"Two cheap little squashed mangoes (p. 38)."

"Impressionable, malcontented, ambitious individuals (p. 58)."

"Lofty illuminated blue signage. (p. 103)."

"Beautiful orange polluted sky (p. 145)."

"Stark and dry and contaminated (p. 223)."

Thus, it may be concluded that the adjectives are arranged in a variety of different orders to add versatility to the expression of truth in the fictional setting of this narrative.

\section{Conclusion}

Stylistic analysis has helped the researcher in collecting evidences for the subjective interpretation of data and the present study has opened up many dimensions of exploration for the future students and researchers.

The study answers the research questions in the following ways:

The first question that the research tried to answer was related to the kind of adjectives chosen by Hamid in the novel under lexical analysis. The adjectives according to kinds are presented in discussion section. Hamid's adjectives are foregrounded in the physical, emotive, color, vocal and auditory attributes. By doing so, he is able to achieve the function of a thorough representation of his characters in the personal and social structure of the context. Another peculiarity of his style is the use of grading adverbs with the base form of adjectives that has enabled the author to achieve realism in the portrayal of his characters and situations. Moreover, the sequence of adjectives in a sentence is also unique at different places in the novel adding variety of description and killing any kind of monotony that may arise in case otherwise. Another marked feature of this novel is the use of attributive adjectives and predicative adjectives. The former ones are descriptive in nature performing the communicative function between the author and the reader. Predicative adjectives are mostly used by the author when a particular mood or behavior of a character is to be highlighted.

Thus the research answers the other two questions as well. The effective use of adjectives is utilized by Hamid to present a realistic account of the fictional world of Asia and thus his lexical choices have helped him in achieving a peculiarity of style as a novelist with his exclusive use of adjectives in How to Get Filthy Rich in Rising Asia.

The present research is pedagogically significant in the sense that it may help the students of both linguistics and literature to come and observe how these two areas of study are interlinked with one another and also, supplement each other. It is an effort to create interest and exposure to the students of literature to equip themselves with the tools and knowledge to succeed in the literary arena with the use of stylistics. 
In addition to the above mentioned significance, this research has added value to the study of literature with profound linguistic knowledge. It is a sincere effort to acknowledge the valuable endeavors of Pakistani authors in the creation of fiction writing. The research has offered another dimension of how research in Pakistani literature in English can be carried out through the interplay of language and literature. It is a kind of a signpost from where the future students and researchers can carry forward the task of exploration to multiple horizons and avenues of knowledge and literary interpretation.

\section{References}

AsimMahmood, D., Mahmmod, R., \& Nawaz, S. (2014). A Corpus Driven Study of Adjectives in Sidhwa's Fiction. Global Journal of Human-Social Science Research, 14(2).

Baker, M. C. (2003). Lexical categories: Verbs, nouns and adjectives (Vol. 102). Cambridge: Cambridge University Press. https://doi.org/10.1017/CBO9780511615047

Biber, D. (2011). Corpus Linguistics and the Study of Literature, Back to the Future. Scientific Study of Literature, 1(1), 15-23. https://doi.org/10.1075/ssol.1.1.02bib

Biber, D., \& Conrad, S. (2009). Register, Genre and Style. Cambridge: Cambridge University Press. https://doi.org/10.1017/CBO9780511814358

Biber, D., Johanssan, S., Leech, G., \& Conrad, E. (1999). The Longman Grammar of Spoken and Written English. London: Longman.

Bolinger, D. (1967). Adjectives in English: attribution and predication. Lingua, 18, 1-34. https://doi.org/10.1016/0024-3841(67)90018-6

Bradford, R. (1997). Stylistics. Hove, UK: Psychology Press.

Chao, G. (2014). You, Me, and Our South Asian Rags-to-Riches Saga: Second-Person Narration and the Self-Help Structure in How to Get Filthy Rich in Rising Asia. Stanford Journal of Asian American Studies, 6, 21-28. Retrieved from http://aas.stanford.edu/journal/papers/SJAAS_V6.pdf

Chapman, R. (1973). Linguistics and Literature, An Introduction to Literary Stylistics. London: Edward Arnold.

Crystal, D., \& Davy, D. (1976). Investigating English style. London: Longman.

Hamid, M. (2013). How to Get Filthy Rich in Rising Asia.

Hough, G. (1969). Style and Stylistics. London: Routledge \& Kegan Paul; New York: Humanities Press.

Kakutani, M. (2013). Love and Ambition in a Cruel New World: How to Get Filthy Rich in Rising Asia by Mohsin Hamid. The New York Times. Retrieved from http://www.nytimes.com/2013/02/22/books/how-to-get-filthy-rich-in-rising-asia-by-mohsin-hamid.html?pa gewanted=all\&_r=0

Khan, G. K. (2013). Narrating Pakistan transnationally: identity, politics and terrorism in Anglophone Pakistani literature after " $9 / 11$ " ( $\mathrm{PhD}$ thesis, University of Warwick). Retrieved from http://wrap.warwick.ac.uk/id/eprint/66150

Leech, G., \& Short, M. (1981). Style in fiction: A linguistic introduction to English fictional prose. London: Longman.

Leech, G., \& Short, M. (2007). Style in Fiction. Britain. Pearson Education Limited, Longman.

Leech, G. (2007). Style in Fiction Revisited: The Beginning of Great Expectations. Style, 41(2), 117-132.

Leech, G. (2008). Language in Literature. Style and Foregrounding. London: Routledge.

Li, M. (2009). The Stylistic Analysis of magazine advertisement-Atkin chocolate chip granola bar. Journal of Asian Social Sciences, 63-69. http://dx.doi.org/10.5539/ass.v5n9p63

Payne, J., Huddleston, R., \& K. Pullum, G. (2010). The distribution and category status of adjectives and adverbs. Word Structure, 3(1), 31-81. https://doi.org/10.3366/E1750124510000486

Shaikh, U. N. (2011). Role of Stylistics in Learning English as a Second Language. Language in India, II, 259-272.

Simpson, P. (2004). Stylistics: A resource book for Students. London \& New York: Routledge, Taylor \& Francis group. 
Starcke, F. B. (2010). Corpus Linguistics in Literary Analysis. London. Continuum. Pakistan Journal of History \& Culture, XXVIII(1), 121-153.

Traugott, E., \& Pratt, M. L. (1980). Linguistics for students of Literature. New York: Harcourt Brace Jovanovich. Wyne, M. (2005). Developing Linguistic Corpora: A guide to good practice. Oxford: Oxbow Books.

\section{Copyrights}

Copyright for this article is retained by the author(s), with first publication rights granted to the journal.

This is an open-access article distributed under the terms and conditions of the Creative Commons Attribution license (http://creativecommons.org/licenses/by/4.0/). 